\title{
Episodic paroxysmal hemicrania: a further case and review of the literature
}

\author{
J N Blau, $H$ Engel
}

\begin{abstract}
Episodic paroxysmal hemicrania was delineated as a clinical entity only two years ago, separating patients whose attacks remained grouped in bouts lasting weeks, from those who started irregularly and lapsed into chronicity or began and continued in the chronic state. $A$ further case of the episodic variety and a review of the nine previously recorded cases is reported. The division into episodic and chronic variants of paroxysmal hemicrania conforms with the classification of cluster headache. The similarity of the two conditions is emphasised although the response to indomethacin in paroxysmal hemicrania is a special feature.
\end{abstract}

Chronic paroxysmal hemicrania, ${ }^{1}$ because of its dramatic response to indomethacin, has therapeutic and conceptual significance to the whole field of headache. Episodic paroxysmal hemicrania, a new term coined by Kudrow, Esperanca and Vijayan ${ }^{2}$ for patients whose attacks remain grouped without becoming chronic, may simplify the classification so that paroxysmal hemicrania, like cluster headache, would be divisible into episodic and chronic varieties. We record here a further patient and review all 10 cases of episodic paroxysmal hemicrania reported so far, and discuss its relationship to cluster headache.

\section{Case report}

A 40 year old housewife and home visitor had experienced recurrent headaches from the age of 16 , which occurred at intervals of three months to three years, each bout lasting 11 to 13 weeks: during the first and third month she had two to three attacks by day but none at night; in the second month attacks reached a peak in frequency and severity occurring hourly throughout the day and waking her at night.

Individual attacks usually lasted $10 \mathrm{~min}$ utes, up to a maximum of 20 minutes. A deep seated, intense pain "as if being scalded by boiling water", not throbbing in character, invariably affected the right, never the left side of the head, beginning behind the eye extending to the temple, the side of the neck and at times to the right parietal region. Her face became pale, the affected eye often watered but was not red, the palpebral fissure narrowed and the right nostril felt blocked without discharge. The pain was unaffected by coughing or bending, but sneezing could give temporary relief. She felt a need to keep busy and move around, frequently leaning against a cold wall. She also applied a cold flannel to the head, or pressed a finger or fist into the affected eye, at times bruising the temple or the lower eyelid. Occasionally she pushed a cotton tip into the right nostril knowing that it did not help but "to try to do something". Severe attacks caused sweating all over the trunk and bilaterally in the face. She often felt suicidal.

During a cluster period a hot bath could trigger an attack. She did not stop working although she might take a few days holiday in her "suicide month"; if an attack occurred in a patient's home she excused herself to go to the toilet during a severe pain. She became very apprehensive about the next attack. Alcohol did not provoke an attack, in fact she used it at times to get a better night's sleep. There was no seasonal or menstrual relationship.

A brain scan and ophthalmic investigations in the past had revealed no abnormality. A collar, physiotherapy to the neck and dental treatment produced no benefit; ergotamine suppositories, tablets of paracetamol, mefenamic acid, clonidine or pizotifen were ineffective. Examination showed no abnormal signs in the central nervous system or on general medical examination. The blood pressure was normal; there was no bruits over the major vessels.

When first seen at the City of London Migraine Clinic in 1985 a diagnosis of cluster headache was made. A course of prednisolone beginning with $40 \mathrm{mg}$ daily and steadily reducing over the next three weeks gave complete relief which she described as "marvellous-never felt better". She remarked that for the first time a doctor believed her story and did not give her the impression that she was mad.

At her next attendance at the Migraine Clinic in 1986 during a further episode, a diagnosis of paroxysmal hemicrania was made: indomethacin $25 \mathrm{mg}$ three times daily, started during the first month of the attack, gave complete relief. In the next bout in 1988 her general practitioner prescribed the same dose of indomethacin which reduced the severe pain so that during the second month the frequency and severity of pain became similar to that during the first and third month of the cluster. This incomplete response, amounting to an $80-90 \%$ reduction,
Received 10 July 1989 and in revised form 5 October 1989 
Table Features of 10 recorded cases of EPH

\begin{tabular}{|c|c|c|c|c|c|c|c|c|c|c|}
\hline Case No & 1 & 2 & 3 & 4 & 5 & 6 & 7 & 8 & 9 & 10 \\
\hline $\begin{array}{l}\text { Author reference } \\
\text { Sex }\end{array}$ & $\stackrel{3}{M}$ & $\stackrel{4}{M}$ & $\mathrm{~F}^{2}$ & $\mathbf{F}$ & $\mathbf{F}$ & $\stackrel{2}{M}$ & $\stackrel{2}{M}$ & $\stackrel{2}{M}$ & $\stackrel{5}{M}$ & $\begin{array}{l}\text { This report } \\
\text { F }\end{array}$ \\
\hline $\begin{array}{l}\text { Age at presentation } \\
\text { Age at onset } \\
\text { Hemicrania }\end{array}$ & $\begin{array}{l}52 \\
18 \\
\mathrm{~L}\end{array}$ & $\begin{array}{l}29 \\
26 \\
\mathbf{R}\end{array}$ & $\begin{array}{l}33 \\
12 \\
\mathrm{~L}\end{array}$ & $\begin{array}{l}76 \\
51 \\
1\end{array}$ & $\begin{array}{l}29 \\
21 \\
\mathrm{~L}\end{array}$ & $\begin{array}{l}42 \\
14 \\
\mathrm{R}\end{array}$ & $\begin{array}{l}44 \\
27 \\
\mathbf{R}\end{array}$ & $\begin{array}{l}55 \\
37 \\
\mathbf{R}\end{array}$ & $\begin{array}{l}59 \\
42 \\
\mathrm{R}\end{array}$ & $\begin{array}{l}40 \\
16 \\
\mathrm{R}\end{array}$ \\
\hline $\begin{array}{l}\text { Duration of episodes (weeks) } \\
\text { Duration of remission (months) }\end{array}$ & $\begin{array}{l}3-8 \\
1 \frac{1}{2}-5\end{array}$ & $\begin{array}{l}4-12 \\
3-12\end{array}$ & $4-6$ & ${ }_{3-6}^{12-16}$ & 24 & $\begin{array}{l}4 \\
3-5\end{array}$ & $\begin{array}{r}8 \\
11\end{array}$ & ${ }_{2-3}^{12-16}$ & $\begin{array}{l}3-4 \\
1-4\end{array}$ & $\begin{array}{r}11-13 \\
3-36\end{array}$ \\
\hline $\begin{array}{l}\text { Maximum frequency of paroxysms } \\
\text { per day } \\
\text { Duration of paroxysms (mins) }\end{array}$ & $\begin{array}{l}20 \\
10-30\end{array}$ & $\stackrel{30}{\rightarrow 20}$ & $\begin{array}{l}20 \\
10-15\end{array}$ & $\stackrel{6}{15-20}$ & $\stackrel{15}{5-15}$ & $\begin{array}{l}8 \\
20-30\end{array}$ & $\begin{array}{l}9 \\
1-20\end{array}$ & $\stackrel{30}{\rightarrow 15}$ & ${ }_{5-10}^{10}$ & $\begin{array}{l}23 \\
10-20\end{array}$ \\
\hline $\begin{array}{l}\text { Efficiency of indomethacin } \\
\text { within }\end{array}$ & $\begin{array}{l}\text { Full } \\
24 \mathrm{~h}\end{array}$ & 0 & $\begin{array}{l}\text { Full } \\
24 \mathrm{~h}\end{array}$ & $\begin{array}{l}\text { Full } \\
24 \mathrm{~h}\end{array}$ & $\begin{array}{l}\text { Full } \\
24 \mathrm{~h}\end{array}$ & $\begin{array}{l}\text { Full } \\
24 \mathrm{~h}\end{array}$ & $\begin{array}{l}\text { Full } \\
24 \mathrm{~h}\end{array}$ & $\begin{array}{l}\text { Full } \\
24 \mathrm{~h}\end{array}$ & $\begin{array}{l}\text { Full } \\
24 h\end{array}$ & $\begin{array}{l}\text { Full } \\
24 h\end{array}$ \\
\hline
\end{tabular}

we attributed to her needing a larger dose of indomethacin.

A further episode, early in 1989, partially responded to $25 \mathrm{mg}$ of indomethacin thrice daily. After three days we advised doubling the dose to $50 \mathrm{mg}$ three times a day which gave total relief. After two days on the larger dose she was able to reduce the medication to $25 \mathrm{mg}$ thrice daily. On this occasion she needed $150 \mathrm{mg}$ of ranitidine to stop her dyspepsia.

\section{Review of all 10 cases reported so far}

The table shows that six males and four females were affected for three to 34 (mean 20) years. The frequency of attacks ranged from six to 30 (mean 17) per day with a mean duration of 15 minutes presumably at the height of bouts. With the exception of one case all had total pain relief from indomethacin in sufficient dosage (part of the definition of the condition), two responded to aspirin, one to ibuprofen and one to corticosteroids. Failure of treatment responses included ergot (4), methysergide (3), oxygen inhalation (2) and corticosteroids (1).

\section{Discussion}

Is episodic paroxysmal hemicrania an entity? Attacks remaining episodic for three to 34 years without progressing to a chronic phase, argues in favour of the condition being an entity in its own right. If correct, then "episodic paroxysmal hemicrania" is preferable to "pre-chronic paroxysmal hemicrania", because the prognostic implication may be incorrect. Nevertheless diligent follow up is indicated: we have seen one patient whose monthly attacks were related to menstruation for 10 years, but in the last year have converted to the chronic variety without remissions (Blau, unpublished).

Are episodic paroxysmal hemicrania and cluster headaches related?

Although the daily frequency and duration of individual attacks differ, the quality and distribution of pain are the same; the accompanying epiphora and the ipsilateral nasal congestion or discharge are common features to both conditions; further, during each variety of attacks patients are restless-walking round the room, or rocking if they sit, as well as pressing on the painful site with one or both hands, even hitting the head against a wall. In each condition patients contemplate suicide because of the severity of the pain: our patient spontaneously described her "suicide month" at the height of her attacks.

Our patient showed a gradual increase of attacks over a month, maximum number of attacks in the second month, and steady diminution during the third month. This pattern is also seen in cluster headache where although noted, it has not been studied ${ }^{67}$ or explained. An overlap in duration of attacks is clearly evident. ${ }^{1}$ Further, Sjaastad who initially described chronc paroxysmal hemicrania with $\mathrm{Dale}^{8}$ stated in $1986^{9}$ "once an attack is established, it is next to impossible to distinguish clinically between a cluster headache and one of chronic paroxysmal hemicrania".

We therefore suggest that cluster headache and paroxysmal hemicrania are similar conditions but, in the latter, attacks are divided into shorter episodes: perhaps there is a local accumulation of a neuro-vascular transmitter which if discharging 1-2 times daily gives rise to prolonged attacks of cluster headache, but if released 10-20 times a day then paroxysmal hemicranial attacks result. However, the differing responses to indomethacin which is only rarely effective in cluster headache, is a point against this notion.

Paroxysmal hemicrania is a clinical entity, some patients beginning with a chronic phase, others remaining episodic, and others who start irregularly (one to two attacks a week) and then progress to chronicity. We support the term episodic for those patients who show clear remission periods, ${ }^{210}$ chronic for those who do not remit, and recommend that pre-chronic is no longer used.

1 Sjaastad $\mathrm{O}$. Chronic paroxysmal hemicrania: clinical aspects and controversies. In: Blau JN, ed. Migraine-clinical, herapeutic, conceptual and research aspects. London: Marshall and Hall 1987: 135-52.

2 Kudrow L, Esperanca P, Vijayan N. Episodic paroxysmal hemicrania? Cephalalgia 1987;7:197-201.

3 Geaney DP. Indomethacin-responsive episodic cluster headache. $J$ Neurol Neurosurg Psychiatry 1983;46:860-1. headache. Neurol Neurosurg Psychiatry 1983;46:860-1. ogucki A, Niewodniczy A. Case report: chronic cluster headache with unusual high frequency of attacks. Dif ferential diagnosis with CPH. Headache 1984;24:150-1. pierings ELH. The chronic paroxysmal

cept expanded. Headache 1988;28:597-8.
Ekbom K. A clinical comparison of cluster headache and migraine. Acta Neurol Scand 1970;46(suppl 41):1-48.

migraine. Acta Neurol Scand 1970;46(suppl 41):1-48.
Kudrow L. Cluster headache: mechanisms and management. Kudrow L. Cluster headache: mechanisms

Oxford: Oxford University Press, 1980.
Sjaastad O, Dale I. Evidence for a new (?) treatable headache entity. Headache 1974;14:105-8.

9 Sjaastad $\mathrm{O}$. Chronic paroxysmal hemicrania (CPH). In: Rose FC, ed. Handbook of clinical neurology. Amsterdam: Elsevier Science Publishers, Vol 4 (48) 1986:257-66.

10 Pearce SHS, Cox JGC, Pearce JMS. Chronic paroxysmal hemicrania, episodic headaches and classical migraine in one patient. J Neurol Neurosurg Psychiatry 1987;50: 1699-70. 